\title{
ECG Brugada type 2 : ST+ en selle
}

\section{Brugada type 2 ECG: saddle-back pattern}

\section{P. Taboulet}

Reçu le 6 octobre 2013; accepté le 28 octobre 2013

(C) SFMU et Springer-Verlag France 2013

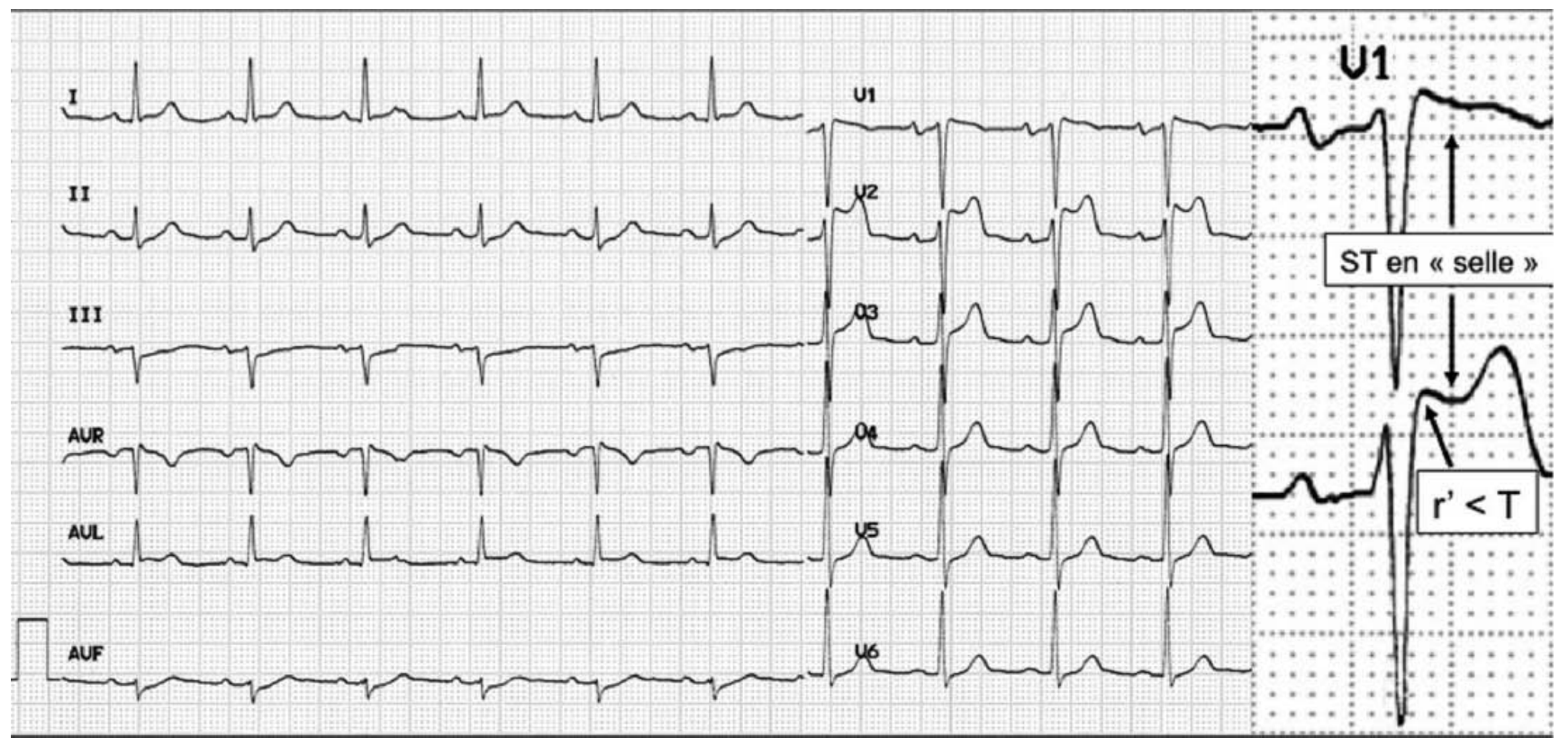

Fig. 1 Complexe QRS élargi en V1V2 qui se termine par une onde r' $\geq 2 \mathrm{~mm}$ de la ligne de base et se poursuit par un segment ST-T en selle. Notez aussi l'absence d'onde s élargie en V6 (« mismatch V1-V6»)

Un patient de 50 ans, sans antécédent, consulte aux urgences après un malaise sans douleur, avec vomissement et sueurs. Son ECG présente un sus-décalage du segment ST en précordiales droites, sans miroir, stable pendant plusieurs heures. Il fait évoquer plusieurs diagnostics : un syndrome coronaire aigu, une variante ST de la normale, et un «ECG Brugada ». Cette dernière hypothèse sera retenue au terme de la consultation, car l'ECG correspond parfaitement à un type $2 \mathrm{du}$ syndrome de Brugada tel qu'il a été redéfini en 2012 [1]. Le complexe QRS en dérivations V1V2 se termine par une « onde r' », dont le sommet arrondi est situé à $\geq$

P. Taboulet $(\bowtie)$

Hôpital Saint-Louis, Assistance publique-hôpitaux de Paris,

service des urgences, 1, avenue Claude Vellefaux,

F-75010, Paris, France

e-mail : pierre.taboulet@sls.aphp.fr
$2 \mathrm{~mm}$ de la ligne de base et dont la pente descente est ralentie et fusionne avec un segment ST descendant court, situé à $\geq$ $0,5 \mathrm{~mm}$ de la ligne de base. À la fin du ST en V2, l'onde T positive est plus ample que le segment ST et crée un aspect en selle de cheval ou dos d'âne (saddle-back) (Fig. 1). Il n'est pas possible de conclure - à ce stade - à un «syndrome de Brugada " car le malaise n'est pas spécifique (absence de syncope, signes vagaux) et l'ECG n'est pas de type 1 (ST+ en dôme en V1V2). Il convient donc d'adresser ce patient à un centre cardiologique spécialisé.

\section{Référence}

1. Bayés de Luna A, Brugada J, Baranchuk A, et al (2012) Current electrocardiographic criteria for diagnosis of Brugada pattern: a consensus report. J Electrocardiol 45:433-42 